\title{
Cfpaper-4023
}

\section{Electron Power Deposition Measurements During Ion Cyclotron Range of Frequency Heating on C-Mod}

\author{
G. Taylor, B. LeBlanc, C.K. Phillips, G. Schilling, J.R. Wilson \\ Plasma Physics Laboratory, Princeton University, Princeton, \\ New Jersey 08543
}

\author{
A. Hubbard, P. Bonoli, E. Nelson-Melby, S.J. Wukitch \\ Massachusetts Institute of Technology, Cambridge, Massachusetts 02139
}

Abstract A 19-channel electron cyclotron emission (ECE) grating polychromator has been added to the existing ECE diagnostics on C-Mod, which include a 9-channel polychromator, heterodyne radiometer and Michelson interferometer. The new instrument can significantly improve the radial resolution of electron power deposition measurements in ICRF experiments on C-Mod. The improved resolution is important for resolving electron power deposition in off-axis mode conversion heating regimes where the mode conversion region can be narrow. The first data from this new instrument were acquired last year during $80 \mathrm{MHz}$ hydrogen minority $\mathrm{D}-\mathrm{H}$ mode conversion experiments where the $\mathrm{H} /(\mathrm{H}+\mathrm{D})$ ratio was varied from 0.02 to 0.30 and the toroidal field was varied from 5.1 to $5.7 \mathrm{~T}$. Although complicated by the presence of large sawteeth, some electron power deposition results were obtained from a break-in-slope method. These results, together with results from data acquired during the current C-Mod experimental campaign, will be presented and compared to predicted radial deposition profiles from the TORIC, 2-D full wave RF code, and the METS95, 1-D integral wave RF code.

\section{INTRODUCTION}

The C-Mod tokamak is a high field $\left(B_{o} \leq 8 \mathrm{~T}\right)$, high density $\left(\mathrm{n}_{\mathrm{e}} \sim 3 \times 10^{20} \mathrm{~m}^{-3}\right)$ device with a major radius of $0.67 \mathrm{~m}$ and a minor radius of $0.21 \mathrm{~m}$ [1]. Ion cyclotron range of frequency (ICRF) heating is the only source of heating, other than ohmic heating. ICRF heating experiments conducted during 1998 used 2-3 MW of $80 \mathrm{MHz}$ RF power launched from two 2-strap fast wave antennas [2]. Experiments were performed in both $\mathrm{D}(\mathrm{H})$ and $\mathrm{D}\left({ }^{3} \mathrm{He}\right)$ plasmas. Also in 1998 , a 19-channel electron cyclotron emission (ECE) grating polychromator (GPC-2) [3] was added to the existing ECE diagnostics on C-Mod, which include a 9-channel GPC (GPC-1) [4]. The addition of GPC-2 can significantly improve the radial resolution of RF power deposition measurements. This paper discusses measurements of the power deposition directly to electrons made during $D(H)$ experiments. These measurements are compared to radial power deposition profiles predicted by the TORIC, 2-D full wave RF code [5] and the METS95, 1D integral RF code [6].

\section{DIRECT ELECTRON HEATING MEASUREMENTS}

To enable the measurement of the RF power deposition to the plasma, the ICRF power was amplitude modulated at a frequency of about $55 \mathrm{~Hz}$ and the RF power deposited directly to electrons was measured with the "break-in-slope" method [7] at the RF power transitions. This method was complicated by the 


\section{DISCLAIMER}

This report was prepared as an account of work sponsored by an agency of the United States Government. Neither the United States Government nor any agency thereof, nor any of their employees, make any warranty, express or implied, or assumes any legal liability or responsibility for the accuracy, completeness, or usefulness of any information, apparatus, product, or process disclosed, or represents that its use would not infringe privately owned rights. Reference herein to any specific commercial product, process, or service by trade name, trademark, manufacturer, or otherwise does not necessarily constitute or imply its endorsement, recommendation, or favoring by the United States Government or any agency thereof. The views and opinions of authors expressed herein do not necessarily state or reflect those of the United States Government or any agency thereof. 


\section{DISCLAIMER}

Portions of this document may be illegible in electronic image products. Images are produced from the best available original document. 
presence of large, frequent sawtooth crashes, which were often close to and, in some cases, locked to the times of the RF power transitions. As a result, only a relatively few cases from the hydrogen concentration scan, which included about 20 plasmas, were found suitable for analysis.

The electron temperature profile response was measured simultaneously by GPC-1 and GPC-2. Both GPCs were cross calibrated to an ECE Michelson interferometer [8]. For various reasons, only about 11 channels of GPC-2 data were useable for these experiments, so that, in total, there were approximately 20 radial channels of electron temperature data available for analysis. The deposition data presented here are from plasmas with an axial toroidal field, $\mathrm{B}_{\mathrm{o}}=5.45 \mathrm{~T}$, where the $H$ concentration, $n_{H} /\left(n_{H}+n_{D}\right)$, was varied from approximately $2 \%$ to $30 \%$ as derived from neutral particle analysis.

Figure 1(a) shows the measured profile of RF power deposition directly to electrons per MW of RF power incident on the plasma versus major radius, for a discharge with a measured $n_{H} /\left(n_{H}+n_{D}\right)=11.5 \%$. The power deposition is peaked on the magnetic axis and reaches a level of $3 \mathrm{MW} / \mathrm{m}^{3} / \mathrm{MW}_{\text {inc. Figure } 1(\mathrm{~b}) \text { shows }}$ the same data mapped to normalized minor radius (r/a). About $14 \%$ of the RF power is deposited directly to electrons within $\mathrm{r} / \mathrm{a}=0.3$. Figure $2(\mathrm{a})$ shows the measured RF power deposition directly to electrons for a discharge with a measured $n_{H} /\left(n_{H}+n_{\mathrm{D}}\right)=28 \%$. The power deposition profile is much broader than in the plasma with the lower hydrogen concentration, but it remains peaked on the magnetic axis. The measured RF power deposition directly to electrons on axis is 1.1 MW/m $/ \mathrm{m}^{3} / \mathrm{MW}_{\text {inc }}$, as shown in Fig. 2(b). About $20 \%$ of the RF power is deposited directly to electrons within $\mathrm{r} / \mathrm{a}=0.6$.

Figure 3 summarizes the directly measured RF power deposition data for plasmas with measured $n_{H} /\left(n_{H}+n_{D}\right)$ concentrations between $2.5 \%$ and $28 \%$. The axial electron heating power density per MW of RF power incident on the plasma fell with increasing hydrogen concentration, from $6.5 \mathrm{MW} / \mathrm{m}^{3} / \mathrm{MW}_{\text {inc }}$ at $\mathrm{n}_{\mathrm{H}} /\left(\mathrm{n}_{\mathrm{H}}+\mathrm{n}_{\mathrm{D}}\right)=2.5 \%$ to $1.1 \mathrm{MW} / \mathrm{m}^{3} / \mathrm{MW}_{\text {inc }}$ at $\mathrm{n}_{\mathrm{H}} /\left(\mathrm{n}_{\mathrm{H}}+\mathrm{n}_{\mathrm{D}}\right)=28 \%$. This result is consistent with an earlier analysis of this data set which calculated the RF power flowing directly to electrons at the magnetic axis from the rate of rise in the central electron pressure corrected for ohmic and radiation contributions immediately after a sawtooth crash [9]. The measured fraction of RF power incident on the plasma which was absorbed globally by electrons ranged between $14 \%$ and $20 \%$.

\section{COMPARISON TO MODELS}

The RF power deposition measurements discussed above were compared to predicted radial deposition profiles from TORIC, a toroidal, 2-D full wave ICRF code which explicitly solves for mode conversion to the ion Bernstein wave (IBW) [5]. A single toroidal mode number of 10 simulated the toroidal mode spectrum of the C-Mod antennas. A somewhat lower $n_{H} /\left(n_{H}+n_{D}\right)$ concentration was used in TORIC than was measured by neutral particle analysis, since using the measured $\mathrm{n}_{\mathrm{H}} /\left(\mathrm{n}_{\mathrm{H}}+\mathrm{n}_{\mathrm{D}}\right)$ concentration in the TORIC simulation placed the mode conversion heating at a larger normalized radius than implied from the $R F$ power deposition measurements. Figure 1(c) shows the results of the TORIC simulation for the nominally $\mathrm{n}_{\mathrm{H}} /\left(\mathrm{n}_{\mathrm{H}}+\mathrm{n}_{\mathrm{D}}\right)=11.5 \%$ plasma, this simulation actually used $\mathrm{n}_{\mathrm{H}} /\left(\mathrm{n}_{\mathrm{H}}+\mathrm{n}_{\mathrm{D}}\right)=7 \%$. About $87 \%$ of the RF power incident on the plasma is absorbed 
by the $\mathrm{H}$ minority. The minority tail energy is not measured on C-Mod, but it is expected to be $\leq 50 \mathrm{keV}$, so that minority heating power probably flows predominantly to the bulk ions. The peak of the minority absorption is on axis, where the power deposition reaches $26 \mathrm{MW} / \mathrm{m}^{3} / \mathrm{MW}_{\text {inc. Mode conversion to IBW }}$ accounts for only $9 \%$ of the absorbed RF power. This power directly heats the electrons at $\mathrm{r} / \mathrm{a} \sim 0.1$, where the power deposition peaks at about 3 $\mathrm{MW} / \mathrm{m}^{3} / \mathrm{MW}_{\text {inc. }}$ The measured deposition in Fig. 1(b) is more peaked. Since only about $1 \%$ of the incident RF power is deposited directly to electrons near the axis as a result of electron Landau damping (ELD), this suggests that there is some contribution to the break-in-slope analysis from the minority heating on axis. The METS95, 1-D integral wave RF code [6] calculated the single pass absorption for this case. $40 \%$ of the incident RF power was absorbed on the first pass of the plasma and about $5 \%$ of the incident RF power was deposited directly to electrons on the first pass. So the power split between electron and ion heating calculated by METS95 is in relatively good agreement with the TORIC simulation for this case.

Figure 2(c) shows the TORIC results for the nominally $\mathrm{n}_{\mathrm{H}} /\left(\mathrm{n}_{\mathrm{H}}+\mathrm{n}_{\mathrm{D}}\right)=28 \%$ plasma, this simulation used $n_{H} /\left(n_{H}+n_{D}\right)=20 \% .83 \%$ of the $R F$ power incident on the plasma is absorbed by the $\mathrm{H}$ minority. The peak of the minority absorption is on axis, where the power deposition reaches $16 \mathrm{MW} / \mathrm{m}^{3} / \mathrm{MW}_{\mathrm{inc}}$. Mode conversion to IBW accounts for $15 \%$ of the absorbed RF power and this directly heats the electrons at $\mathrm{r} / \mathrm{a} \sim 0.3$ where the power deposition peaks at about 1.5 $\mathrm{MW} / \mathrm{m}^{3} / \mathrm{MW}_{\text {inc }}$. About $1 \%$ of the incident RF power is deposited on axis directly to electrons as a result of ELD. The deposition measurements in Fig. 2(b) indicate there is a broad power deposition to electrons centered on-axis. So, once again there appears to be some contribution from the minority heating to the break-inslope analysis near the axis. For this case, METS95 calculates that $16 \%$ of the incident RF power was absorbed by the plasma and $4 \%$ of the incident RF power was absorbed directly by electrons on the first pass.

\section{ACKNOWLEDGMENTS}

This work was supported by US DoE contracts no. DE-AC02-76CH03073 and DE-FC02-99ER54512.

\section{REFERENCES}

[1] Hutchinson, I.H., et al., Phys. Plasmas 1, 1511 (1994)

[2] Takase, Y., et al., Proc. $14^{\text {th }}$ IEEE/NPSS Symp. Fus. Eng. 118 (San Diego, CA, 1995)

[3] Janos, A., et al., Rev. Sci. Instrum. 66, 668 (1995)

[4] O'Shea, P.J., PhD Thesis, MIT (1997)

[5] Brambilla, M. and Krücken, T., Nucl. Fusion 28, 1813 (1988)

[6] Smithe, D.N., et al., AIP Conf. Proc. 403, 367 (1997)

[7] Gambier, D.J., et al., Nucl. Fusion 30, 23 (1990)

[8] Hubbard, A.E., Hsu, T.C., and O'Shea, P.J., Proc. $9^{\text {th }}$ Joint Workshop on ECE and ECH, 387 (Borrego Springs, CA, 1995).

[9] Wukitch, S.J., et al., Paper IAEA-F1-CN-69/CDP/10, Proc. $17^{\text {th }}$ IAEA Fus. Eng. Conf. (Yokohama, Japan, 1998) 

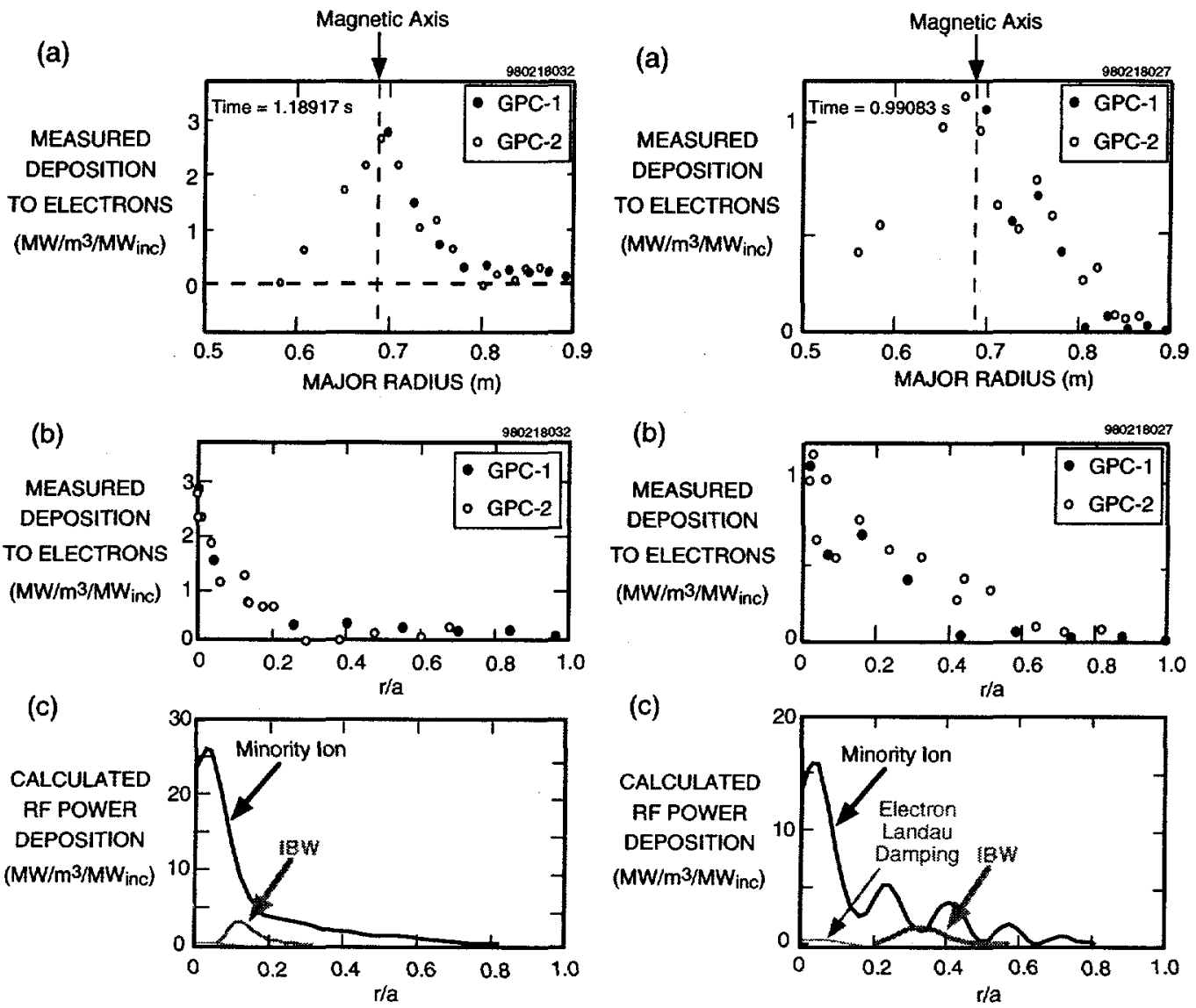

(c)

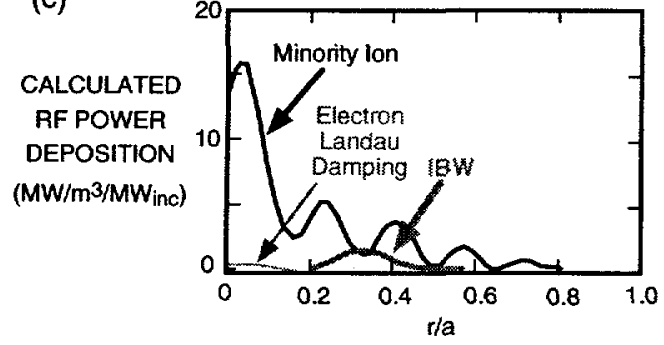

FIGURE 1

Measured direct RF power deposition to electrons per MW of RF power incident on the plasma, versus (a) major radius and (b) normalized minor radius, for a plasma with a measured $n_{H} /\left(n_{H}+n_{D}\right)=11.5 \%$. (c) RF power deposition calculated by the TORIC 2-D, Full wave $R F$ code for $n_{H} /\left(n_{H}+n_{D}\right)=7 \%$.

\section{FIGURE 2}

Measured direct RF power deposition to electrons per MW of RF power incident on the plasma, versus (a) major radius and (b) normalized minor radius, for a plasma with a measured $n_{H} /\left(n_{H}+n_{D}\right)=28 \%$. (c) RF power deposition calculated by the TORIC 2-D, Full wave $R F$ code for $n_{H} /\left(n_{H}+n_{D}\right)=20 \%$.

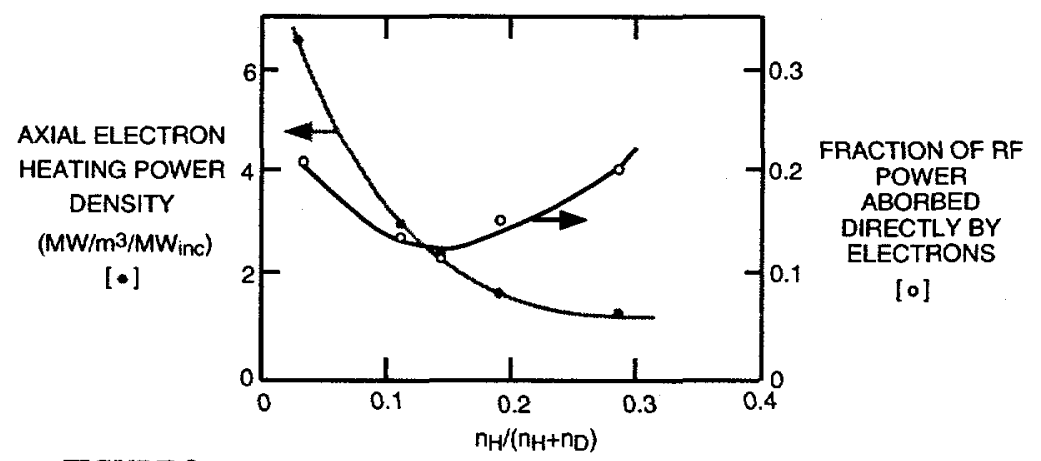

FIGURE 3

Measured axial electron heating power density per MW of RF power incident on the plasma ( $\bullet$ ) and measured fraction of RF power absorbed directly by electrons (o) versus measured $n_{H} /\left(n_{H}+n_{D}\right)$ concentration. The lines are fits to the data points. 